\title{
Oocyte Cryostorage to Preserve Fertility in Oncological Patients
}

\author{
Alberto Revelli, Emanuela Molinari, Francesca Salvagno, Luisa Delle Piane, \\ Elisabetta Dolfin, and Simona Ochetti
}

Phisiopathology of Reproduction and IVF Unit, Department of Ginecological and Obstetrical Sciences, S. Anna Hospital, University of Torino, 10126 Torino, Italy

Correspondence should be addressed to Alberto Revelli, aerre99@yahoo.com

Received 4 October 2011; Accepted 22 November 2011

Academic Editor: Federica Moffa

Copyright ( 2012 Alberto Revelli et al. This is an open access article distributed under the Creative Commons Attribution License, which permits unrestricted use, distribution, and reproduction in any medium, provided the original work is properly cited.

Thanks to the progress in oncostatic treatments, young women affected by cancer have a fairly good chance of surviving the disease and leading a normal post-cancer life. Quite often, however, polychemiotherapy and/or radiotherapy can induce ovarian damage and significantly reduce the content of follicles and oocytes inside the ovary, thus predisposing the patient to menstrual disorders, infertility, and precocious menopause. Several techniques have been proposed to preserve fertility in these patients; among them oocyte collection and cryopreservation prior to the oncostatic treatment has been widely applied in the last decade. The proper indications, the permitting conditions, the available hormonal stimulation protocols, as well as the effectiveness and limits of this option will be discussed herein, with a comprehensive and up-to-date review of the two techniques commonly used to cryostore oocytes, the slow-freezing technique and the vitrification technique.

\section{Introduction}

During the past decade, fertility preservation has become an important issue in cancer patients' management. Survival rates after malignancy treatment have improved markedly, especially for young women affected by melanoma, oncohaematological diseases, and breast cancer, leading to the generation of long-term cancer survivors $[1,2]$; nonetheless, this population is quite frequently affected by iatrogenic infertility and/or premature ovarian insufficiency (POI) [3]. Recent studies, in fact, showed that abdominal radiotherapy may lead to ovarian damage in a dose-dependent fashion; similarly, total body irradiation may result in POI in about $97 \%$ of cases [4]. Chemotherapy regimens, especially those involving alkylating agents, may cause acute loss of follicles within the ovary, leading to hormone deficiency and permanent infertility [5]. Psychological distress induced by the loss of reproductive perspective as well as factors related to a premature menopause (osteoporosis, cardiovascular diseases, depression, etc.) may dramatically affect survived women's quality of life. Although disease remission obviously remains the first goal of cancer treatment, patient's awareness toward safeguarding future fertility is increasing [6].
Many approaches have been considered to preserve fertility and avoid POI. Embryo cryostorage has been considered for years the only valid option, albeit this procedure is applicable only to stable couples and not to singles, and still raises a lot of ethical, legal, and practical concerns. Ovarian cortex ablation and cryostorage, with subsequent autografting, is the only strategy which can be proposed to prepubertal girls, though it is still considered an experimental approach with limited results.

Nowadays, oocyte cryostorage is considered an important tool for fertility preservation worldwide, as no surgery is required and minimally invasive ovarian stimulation protocols are available. Moreover, storing oocytes implies no concerns regarding possible cancer cells contamination, a problem that affects ovarian cortex retransplantation strategy [7]. As a result of oocyte cryostorage and in vitro fertilization (IVF), over 2000 babies were born in nononcological, routine IVF patients.

\section{History of Oocyte Cryostorage}

Since oocyte cryostorage was introduced in the mid 1980s, general interest rose around the possibility of increasing 
pregnancy rates using frozen eggs, overcoming the ethical and legal concerns related to embryo freezing.

Since the very beginning oocyte freezing was quite problematic, with survival and fertility rates below 50\%, and pregnancy rates as low as 1-2\% [8-10]. Chen and Van Uem et al. reported the first pregnancies obtained after oocyte freezing/thawing, raising many expectations in scientific community $[11,12]$. Unfortunately, many other attempts failed to reach the same result [13-15]: oocyte freezing strategy was dramatically less effective than zygote or embryo cryopreservation. Before intracytoplasmatic sperm injection (ICSI) was introduced in most IVF laboratories, the premature release of cortical granules by the frozen oocyte with the consequent irreversible thickening of the zona pellucida was able to halt sperm penetration and impair fertilization $[16,17]$.

Cryobiologists encountered several problems in freezing oocytes, including ice crystal formation, osmotic stress, and cryoprotectant agents (CPAs) toxicity [8, 18, 19]. Compared to other mammalian cells, human mature oocytes are constituted by a very high amount of water and have a small surface-to-volume ratio, which strongly affects cells dehydration that is essential for survival after thawing. Zona pellucida cracking, mitochondria shrinkage, and microfilaments alteration were also addressed as cryostorage-induced injuries on the human oocyte [20]. Moreover, meiotic spindle (MS) disassembly induced by cooling was clearly shown after the introduction of polarized light microscopy analysis. Many authors reported that when oocytes are exposed to low temperatures, the MS disappears from their oocytes, and reappears as a consequence of repolymerization after a few hours of incubation at thawing temperature $[21,22]$. The survival of an oocyte after warming can be assessed when a bright cytoplasm surrounded by an intact zona pellucida is observed; anyway, chilling female gametes to subzero temperatures provides damages to their ultrastructure, as observed by several authors who performed electron microscope analysis: the main consequences of freezing/thawing procedures involve organelle displacement, mitochondrial disruption, vacuolization of the ooplasm, and loss of spindle polarity predisposing to an altered chromosomal alignment [23-25].

Cryobiology aims at minimizing these harmful effects on the human oocyte, and by now, two well-established laboratory protocols have been proposed and are widely diffused in the clinical practice: the slow freezing protocol and the vitrification procedure.

\section{Candidates for Oocyte Cryopreservation}

Fertility preservation should be discussed with all young women at high risk of POI. The most common cause of POI are ovarotoxic anticancer therapies, and cancer patients are by far the main candidates to fertility preservation. However, benign diseases like some genetic syndromes (Turner's syndrome, X-fragile carrier condition, etc.), ovarian diseases (severe endometriosis or ovarian cysts requiring ablative surgery), or autoimmune disorders requiring immunosuppressive therapy may determine POI as well.
Cancer in women in reproductive age is an increasing problem. The American Cancer Society estimates that 1/47 women will develop a cancer before the age of 39 (American Cancer Society, Inc., Surveillance Research 2011). Every year, about 200.000 new cases of breast cancer are diagnosed in USA, $15 \%$ of which occur in women under the age of 45 . Most of these patients will receive adjuvant chemotherapy with alkylating drugs 4 to 6 weeks after surgery, developing a high risk of POI [26] (National Institute of Health Consensus Development Panel, 2001). Many breast cancer cases, however, are hormone-sensitive, and appropriate ovarian stimulation regimens are needed to keep low circulating estrogen levels while stimulating the ovary to cryostore oocytes [27-30]. Haematological malignancies such as lymphoma and leukemia show now quite good survival rates, and the attention is shifting toward the prevention of side effects like infertility [31].

Even nonneoplastic diseases (autoimmune disorders or benign haematologic diseases being treated with chemo- or radiotherapy) should routinely implicate the offer of oocyte cryopreservation $[32,33]$.

The selection of candidates for fertility preservation is crucial in order to offer the best suitable technique for each patient. Oocyte cryopreservation is probably the best technique to preserve fertility of women without an established partner or wishing to avoid ethical and legal problems associated with embryo cryostorage. When feasible, oocyte cryostorage may be preferable to ovarian tissue freezing because it does not require surgery and has already resulted in many live births [9].

The most important limiting factor for oocyte cryopreservation is age: storing oocytes in women after 40 years of age will probably result in a very poor chance to get a pregnancy in the future. Indeed, patients with a poor ovarian reserve have to be screened carefully, since they may not benefit from the treatment. Ovarian reserve assessment is crucial for patients requiring oocyte cryostorage: besides age, the antral follicle count and hormonal parameters such as FSH and anti-Mullerian hormone (AMH) have to be carefully considered. On the other side, oocyte cryopreservation is unavailable for prepubertal girls because the ovarian stimulation used to obtain oocytes needs the full maturity of the hypothalamus-pituitary-ovarian axis.

Another limiting issue is the timing of the procedure: oocyte cryopreservation requires an average of 12 days for ovarian stimulation and ovum pickup (OPU) to occur [34]. Women starting oncostatic therapy in a very short time from diagnosis or having already started chemotherapy may not benefit from oocyte cryostorage.

Oocyte cryopreservation implies a controlled ovarian hyperstimulation with exogenous gonadotropins that leads to largely supraphysiological levels of serum estradiol. Type and stage of the neoplastic disease and the patient's overall health influence the feasibility of an ovarian stimulation, and stimulation protocols must be individualized for every woman. In this perspective, the use of conventional ovarian stimulation protocols is possible only in women with estrogen-insensitive tumours, while hormone-responsive diseases require appropriate regimens [35]. 


\section{Ovarian Stimulation Protocol}

Each protocol that aims at obtaining oocytes for cryostorage should be (i) safe, with limited risk of stimulating the growth of a pre-existing neoplasia, (ii) fast, with very limited delay in starting cancer therapy, (iii) effective, with good chances of oocyte retrieval.

Ovarian stimulation requires approximately 10-14 days to achieve mature oocytes at OPU. In case of estrogensensitive diseases, the protocol with letrozole $(5 \mathrm{mg} /$ day from the second day of menstrual cycle for 5-7 days) plus gonadotropins (150-300 IU of recombinant FSH) and GnRH-antagonists [30] is one of the most recommendable: this regimen allows an acceptable oocyte yield and keeps the circulating estradiol levels rather low [36], a GnRHagonist may be used to trigger the follicle final maturation, minimizing the risk of ovarian hyperstimulation syndrome (OHSS); moreover, letrozole or GnRH-antagonist can be readministered from the day of OPU until blood estradiol concentration falls below $50 \mathrm{pg} / \mathrm{mL}$. In case of shortage of time, alternative regimens include to start stimulation in the luteal phase. Some women, in fact, need an urgent cancer treatment and cannot delay the beginning of the oncostatic therapies until the onset of menstruation; in this case, a GnRH-antagonist is administered to induce an abrupt luteolysis and then gonadotropins are started [37]. The egg retrieval rate is similar to the one observed using longer, conventional stimulation regimens.

A growing literature showing encouraging results of oocyte in vitro maturation (IVM) followed by vitrification for cryostorage is now available [38, 39]. This option consists in the possibility to retrieve immature oocytes from unstimulated preantral follicles, which are arrested in the prophase of the first meiotic division. Immature oocyte retrieval followed by in vitro maturation (IVM) resulted in several live births [40] and it is claimed that live births could be achieved combining oocyte IVM and vitrification. This technique is safe and theorically effective for all oncological patients, as no hormonal stimulation is needed, and it can be performed with no time restrictions [39]. The effectiveness of the procedure appears to be higher when immature oocytes are first matured in vitro and then frozen [41]. The potential of oocyte maturation is, in fact, reduced after vitrification $[42,43]$.

Overall, some data suggest that immature oocytes could be less sensible to cryodamage than mature oocytes because their nuclear apparatus is still not fully developed, and after thawing, they can be matured in vitro to metaphase II $[56,57]$. Cryopreservation of immature oocytes should be considered in oncological patients who cannot undergo hormonal stimulation with high peak estradiol concentrations, for example, patients with breast cancer [58].

\section{Slow Freezing Method}

The slow freezing/rapid thawing method was the first cryostorage protocol adopted for oocytes in IVF laboratories. It was originally introduced with the aim to preserve super- numerary embryos obtained from assisted reproduction procedures $[59,60]$.

Oocyte freezing was initially a damping technique: rates of survival and cleavage after thawing were significantly lower than those obtained using zygote or cleavage stage embryos. The major burden of mammalian egg cryopreservation was found to be membrane permeability to cryoprotectants: after fertilization, in the zygote and in the cleavage-stage embryo, water permeability kinetics change, rendering the cells more prone to freezing [61].

The original protocol introduced for mouse embryo cryopreservation was slightly modified and adapted to human cells [62]. Small permeating molecules, like dimethylsulfoxide (DMSO) or propandiol $(\mathrm{PROH})$, were adopted to allow water substitution in the intracellular compartment and were found to be useful to avoid ice crystal formation within the oocyte's cytoplasm. Sucrose-supplemented media were effective in reducing the shrinking/swelling phenomenon occurring when osmotic imbalance between the intracellular compartment and the extracellular environment is generated. Some authors [63] observed that increasing sucrose concentration from 0.1 to $0.2 \mathrm{M}$ increased oocyte survival and fertilization after thawing; further raising sucrose concentration up to $0.3 \mathrm{M}$ yielded even better results [64]. Sodium replacement with choline in the cryopreservation medium also obtained satisfactory results $[65,66]$.

Another crucial point of the oocyte freezing technique is the rate of freezing, which has to be performed under strictly controlled conditions: room temperature, as well as equilibration temperature of cryopreservation media, is able to interfere with membrane permeability to cryoprotectants, possibly affecting the oocyte survival chance [19]. Moreover, since slow freezing technique slowly dehydrates oocyte cytoplasm, a programmable freezer is required in the laboratory. The cooling rate must reach, starting from room temperature $\left(20^{\circ} \mathrm{C}\right)$, a temperature of $-7 / 8^{\circ} \mathrm{C}$ with a speed of $-2^{\circ} \mathrm{C} / \mathrm{min}$. In order to prevent spontaneous ice crystal formation, at this stage the operator must perform manual seeding by touching the device where oocytes have been previously loaded (usually a plastic straw) with a nitrogencooled object. Subsequently, samples are cooled to $-30^{\circ} \mathrm{C}$ at a speed rate of $-0,3^{\circ} \mathrm{C} / \mathrm{min}$ and then definitively frozen to $-150^{\circ} \mathrm{C}$ at a speed rate of $-50^{\circ} \mathrm{C} / \mathrm{min}$. Differently, the warming rate must be very rapid in order to prevent the recrystallization of intracellular water.

The slow freezing protocol has been considered the gold standard technique for oocyte cryopreservation for years; it is a well-established procedure with survival rates usually as high as $60-80 \%$ (Table 1) [45, 47, 48, 67, 68]. Nevertheless, some authors emphasized the detrimental effects of high sucrose concentration on oocyte cytoplasm organelles and proposed alternative freezing techniques and timing schedules $[23,52,69]$.

Clinical reports on slow freezing show a pregnancy rate ranging between 13 and 20\% (pregnancy/embryo transfer) (Table 1) and implantation rates still low in comparison to those observed in fresh cycles [44]. Grifo and Noyes compared slow freezing to vitrification on sibling oocytes, showing similar results in terms of survival, but higher 
TABLE 1: Results from different oocyte cryopreservation protocols: slow freezing (high-sucrose concentration) and vitrification.

\begin{tabular}{|c|c|c|c|c|c|c|c|}
\hline & $\begin{array}{c}\text { Vitrification } \\
\text { (VIT) }\end{array}$ & $\begin{array}{c}\text { Slow freezing } \\
\text { (SF) }\end{array}$ & Survival & Fertilization & Pregnancy & Miscarriage & $\begin{array}{c}\text { Egg donation } \\
\text { program }\end{array}$ \\
\hline Chen et al., 2005 [44] & - & Yes & $75 \%(119)$ & $67 \%(80)$ & $33 \%(7)$ & $0 \%$ & Partially \\
\hline Li et al., 2005 [45] & - & Yes & $90 \%(73 / 81)$ & $82 \%(60 / 73)$ & $47 \%(7 / 15)$ & $28 \%(2 / 7)$ & Partially \\
\hline Kuwayama et al., 2005 [46] & Yes & - & $91 \%(58 / 64)$ & $81 \%(52 / 64)$ & $41 \%(12 / 29)$ & $17 \%(2 / 12)$ & No \\
\hline Borini et al., 2006 [47] & - & Yes & $\begin{array}{c}43,4 \% \\
(306 / 705)\end{array}$ & $\begin{array}{c}51,6 \% \\
(158 / 306)\end{array}$ & $19,2 \%(14 / 73)$ & $28,6 \%(4 / 14)$ & No \\
\hline Barritt et al., 2007 [48] & - & Yes & $86,1 \%(68 / 79)$ & $89,7 \%(61 / 68)$ & $75 \%(3 / 4)$ & NS & Yes \\
\hline Lucena et al., 2006 [49] & Yes & - & $96,7 \%(143)$ & $87,2 \%(105)$ & $56,5 \%(13)$ & NS & Yes \\
\hline Antinori et al., 2007 [50] & Yes & - & $\begin{array}{c}99,4 \% \\
(328 / 330)\end{array}$ & $\begin{array}{c}92,9 \% \\
(305 / 328)\end{array}$ & $32,5 \%(39 / 120)$ & $20,5 \%(8 / 39)$ & No \\
\hline Cobo et al., 2008 [51] & Yes & - & $\begin{array}{c}96,9 \% \\
(224 / 231)\end{array}$ & $\begin{array}{c}76,3 \% \\
(171 / 224)\end{array}$ & $65,2 \%(15 / 23)$ & $20 \%(3 / 15)$ & Yes \\
\hline Parmegiani et al., 2008 [52] & - & Yes & $\begin{array}{c}75,1 \% \\
(328 / 437)\end{array}$ & $80 \%(227 / 328)$ & $19 \%(16 / 83)$ & $31,2 \%(5 / 16)$ & No \\
\hline \multirow{4}{*}{ Smith et al., 2010 [53] } & \multirow{2}{*}{ Yes } & \multirow{2}{*}{ Yes } & $\begin{array}{l}\text { SF 61\% } \\
(75 / 123)\end{array}$ & $\begin{array}{c}\text { SF } 61,3 \% \\
(46 / 75)\end{array}$ & ND & ND & No \\
\hline & & & $\begin{array}{l}\text { VIT 91,8\% } \\
(268 / 292)\end{array}$ & $\begin{array}{l}\text { VIT } 67,9 \% \\
(182 / 268)\end{array}$ & ND & ND & No \\
\hline & \multirow{2}{*}{ Yes } & \multirow{2}{*}{ Yes } & $\begin{array}{c}\text { SF 65\% } \\
(155 / 238)\end{array}$ & $\begin{array}{c}\text { SF 67\% } \\
(104 / 155)\end{array}$ & SF $13 \%(4 / 30)$ & SF $25 \%(1 / 4)$ & No \\
\hline & & & $\begin{array}{l}\text { VIT 75\% } \\
(260 / 349)\end{array}$ & $\begin{array}{l}\text { VIT 77\% } \\
(200 / 260)\end{array}$ & $\begin{array}{l}\text { VIT 38\% } \\
(18 / 48)\end{array}$ & $\begin{array}{l}\text { VIT } 18 \% \\
(4 / 18)\end{array}$ & No \\
\hline Rienzi et al., 2010 [54] & Yes & - & $97 \%(120 / 124)$ & $79,2 \%(95 / 120)$ & $30,8 \%(15 / 39)$ & $20 \%(3 / 15)$ & No \\
\hline Cobo et al., 2010 [55] & Yes & - & $92,5 \%(3039)$ & $73,3 \%(\mathrm{NS})$ & $55,4 \%(148)$ & NS & Yes \\
\hline
\end{tabular}

NS $=$ Data not reported.

ND = Data not calculated, not a study endpoint.

fertilization and blastocyst formation rates using the former [67].

In standard IVF procedures, cryopreserving oocytes combines the chances to achieve a pregnancy by both fresh and thawing cycles, thus yielding a rather high cumulative pregnancy rate [47].

\section{Vitrification Method}

Early studies on oocyte vitrification were performed at the end of 1980s, when the first attempts on mouse or hamster eggs were reported $[70,71]$. The introduction of oocyte vitrification in human IVF is a relatively recent phenomenon $[46,54,72]$.

The scientific basis of vitrification consists in the ultrarapid freezing of cells, whose intra- and extracellular aqueous environment turns into a glassy-like state. Vitrification combines two different biophysical processes: a preliminary equilibration step, in which oocytes are exposed to low concentrations of cryoprotectants to allow water outflow, and a subsequent vitrification phase in which cells undergo a high osmotic gradient that completes cells dehydration. Under these conditions, oocytes can be directly merged into liquid nitrogen and then stored. Similarly, warming of oocytes must be rapid in order to avoid recrystallization of water.
The cryoprotectants used during vitrification are the same employed for slow freezing, but they are three-to-fourfolds more concentrated in vitrificaton than in slow freezing. DMSO, PROH, and ethylene glycol (EG) (5-6 M) as well as sucrose $(1 \mathrm{M})$ are currently used, though their toxicity is still under evaluation [73].

Appropriate carriers for freezing oocytes are also very important. Successful vitrification occurs when samples are loaded in a minimal fluid volume and then frozen/thawed at an extremely fast rate $\left(1500-2000^{\circ} \mathrm{C} / \mathrm{min}\right)$. Open systems guarantee direct contact with liquid nitrogen $[74,75]$ : openpulled straws, cryo-tops and cryo-loops, cryo-leafs, electron microscopy grids, and many other devices were tested in the last years [39, 46, 76, 77]. All open systems raise some concerns about the possible viral contamination of stored material, either from nitrogen or from cross-contamination among samples [73]: strategies to avoid this risk include the formulation of high-security closed devices, exposure to nitrogen vapors, and nitrogen ultraviolet (UV) sterilization $[55,78]$.

Although no cross-contamination between liquid nitrogen and stored oocytes has been signalled to date, closed systems may provide the safer and probably most effective vitrification procedure. In particular, many carriers have been approved by FDA in the last years, and several of them are now commercially available: Cryotip (Irvine Scientific, CA, USA), high-security vitrification (HSV) straw 
(Cryo BioSystem, Paris, France), VitriSafe (VitriMed, Austria), Cryopette (Origio, Denmark), and Rapid-i (Vitrolife Sweden AB) [79]. DNA integrity assessed on warmed mouse oocytes is comparable in open versus closed vitrification systems; anyway, there is still an ongoing debate whether closed or open vitrification carriers provide the best results in terms of fertilization and cleavage rates [80]. On the other hand, there is wide agreement in considering vitrification an operator-dependent procedure.

Oocyte survival after vitrification reaches $90 \%$ in several reports (Table 1) [38, 42, 46, 49, 50, 54, 81]. Oocyte quality seems to be poorly affected by chilling injury: spindle repolymerization occurs within one hour after warming, suggesting that the ultrastructure of these gametes is better preserved by vitrification rather than slow freezing [82]; moreover, the metabolomic profiling of vitrified oocytes was found to be comparable to the one of fresh eggs $[83,84]$.

Data on the clinical use of vitrified eggs in routine IVF show that pregnancy rates can be comparable to those achieved with fresh oocytes (Table 1) [9, 54, 85]. Studies aimed to compare vitrification and slow freezing reported implantation and pregnancy rates trendly higher with vitrification, although the number of observed cases overall is still too low to draw final conclusions $[42,51,53$, $81,86]$.

\section{Conclusions}

Cryostoring oocytes is an effective method to preserve fertility in postpubertal young women at risk of POI. In the last years, significant improvements in the clinical effectiveness of oocyte freezing/thawing techniques have been achieved using both slow freezing method and vitrification. The available trials comparing these two different approaches are still insufficient to establish the superiority of one over the other, but the growing interest of scientist and the increasing awareness of women about the possibility of storing oocytes will likely lead to the development of an optimal protocol for oocyte storage in the next few years.

\section{References}

[1] M. A. Smith, N. L. Seibel, S. F. Altekruse et al., "Outcomes for children and adolescents with cancer: challenges for the twenty-first century," Journal of Clinical Oncology, vol. 28, no. 15, pp. 2625-2634, 2010.

[2] G. Gatta, G. Zigon, R. Capocaccia et al., "Survival of European children and young adults with cancer diagnosed 1995-2002," European Journal of Cancer, vol. 45, no. 6, pp. 992-1005, 2009.

[3] W. H. B. Wallace, R. A. Anderson, and D. S. Irvine, "Fertility preservation for young patients with cancer: who is at risk and what can be offered?" The Lancet Oncology, vol. 6, no. 4, pp. 209-218, 2005.

[4] W. H. B. Wallace, A. B. Thomson, F. Saran, and T. W. Kelsey, "Predicting age of ovarian failure after radiation to a field that includes the ovaries," International Journal of Radiation Oncology Biology Physics, vol. 62, no. 3, pp. 738-744, 2005.

[5] G. L. Warne, K. F. Fairley, J. B. Hobbs, and F. I. R. Martin, "Cyclophosphamide induced ovarian failure," The
New England Journal of Medicine, vol. 289, no. 22, pp. 11591162, 1973.

[6] K. A. Snyder and W. Pearse, "Discussing fertility preservation options with patients with cancer," Journal of the American Medical Association, vol. 306, no. 2, pp. 202-203, 2011.

[7] T. Tao, W. Zhang, and A. del Valle, "Human oocyte cryopreservation," Current Opinion in Obstetrics and Gynecology, vol. 21, no. 3, pp. 247-252, 2009.

[8] J. J. Stachecki and J. Cohen, "An overview of oocyte cryopreservation," Reproductive BioMedicine Online, vol. 9, no. 2, pp. 152-163, 2004.

[9] K. Oktay, A. P. Cil, and H. Bang, "Efficiency of oocyte cryopreservation: a meta-analysis," Fertility and Sterility, vol. 86, no. 1, pp. 70-80, 2006.

[10] R. Gosden, "Cryopreservation: a cold look at technology for fertility preservation," Fertility and Sterility, vol. 96, no. 2, pp. 264-268, 2011.

[11] C. Chen, "Pregnancy after human oocyte cryopreservation," The Lancet, vol. 1, no. 8486, pp. 884-886, 1986.

[12] J. F. H. M. van Uem, E. R. Siebzehnrubl, and B. Schum, "Birth after cryopreservation of unfertilised oocytes," The Lancet, vol. 1, no. 8535, pp. 752-753, 1987.

[13] S. Al-Hasani, K. Diedrich, H. van der Ven, A. Reinecke, M. Hartje, and D. Krebs, "Cryopreservation of human oocytes," Human Reproduction, vol. 2, no. 8, pp. 695-700, 1987.

[14] J. Mandelbaum, A. M. Junca, M. Plachot et al., "Cryopreservation of human embryos and oocytes," Human Reproduction, vol. 3, no. 1, pp. 117-119, 1988.

[15] S. J. Todorow, E. R. Siebzehnrubl, M. Spitzer, R. Koch, L. Wildt, and N. Lang, "Comparative results on survival of human and animal eggs using different cryoprotectants and freezethawing regimens. II. Human," Human Reproduction, vol. 4, no. 7, pp. 812-816, 1989.

[16] P. L. Matson, J. Graefling, S. M. Junk, J. L. Yovich, and W. R. Edirisinghe, "Cryopreservation of oocytes and embryos: use of a mouse model to investigate effects upon zona hardness and formulate treatment strategies in an in-vitro fertilization programme," Human Reproduction, vol. 12, no. 7, pp. 15501553, 1997.

[17] M. H. Johnson and S. J. Pickering, "The effect of dimethylsulphoxide on the microtubular system of the mouse oocyte," Development, vol. 100, no. 2, pp. 313-324, 1987.

[18] P. Mazur, "Kinetics of water loss from cells at subzero temperatures and the likelihood of intracellular freezing," Journal of General Physiology, vol. 47, pp. 347-369, 1963.

[19] L. de Santis and G. Coticchio, "Theoretical and experimental basis of slow freezing," Reproductive BioMedicine Online, vol. 22, no. 2, pp. 125-132, 2011.

[20] A. H. Sathananthan, A. Trounson, and L. Freeman, "Morphology and fertilizability of frozen human oocytes," Gamete Research, vol. 16, no. 4, pp. 343-354, 1987.

[21] L. Rienzi, F. Martinez, F. Ubaldi et al., "Polscope analysis of meiotic spindle changes in living metaphase II human oocytes during the freezing and thawing procedures," Human Reproduction, vol. 19, no. 3, pp. 655-659, 2004.

[22] Y. Cohen, M. Malcov, T. Schwartz et al., "Spindle imaging: a new marker for optimal timing of ICSI?" Human Reproduction, vol. 19, no. 3, pp. 649-654, 2004.

[23] R. Gualtieri, M. Iaccarino, V. Mollo, M. Prisco, S. Iaccarino, and R. Talevi, "Slow cooling of human oocytes: ultrastructural injuries and apoptotic status," Fertility and Sterility, vol. 91, no. 4, pp. 1023-1034, 2009.

[24] J. J. Bromfield, G. Coticchio, K. Hutt, R. Sciajno, A. Borini, and D. F. Albertini, "Meiotic spindle dynamics in human 
oocytes following slow-cooling cryopreservation," Human Reproduction, vol. 24, no. 9, pp. 2114-2123, 2009.

[25] R. Gualtieri, V. Mollo, V. Barbato, I. Fiorentino, M. Iaccarino, and R. Talevi, "Ultrastructure and intracellular calcium response during activation in vitrified and slow-frozen human oocytes," Human Reproduction, vol. 26, no. 9, pp. 2452-2460, 2011.

[26] G. N. Hortobagyi, "Adjuvant systemic therapy for early breast cancer: progress and controversies," Clinical Cancer Research, vol. 7, no. 7, pp. 1839-1842, 2001.

[27] M. F. M. Mitwally and R. F. Casper, "Use of an aromatase inhibitor for induction of ovulation in patients with an inadequate response to clomiphene citrate," Fertility and Sterility, vol. 75, no. 2, pp. 305-309, 2001.

[28] M. F. M. Mitwally and R. F. Casper, "Aromatase inhibitors for the treatment of infertility," Expert Opinion on Investigational Drugs, vol. 12, no. 3, pp. 353-371, 2003.

[29] M. F. M. Mitwally and R. F. Casper, "Aromatase inhibition reduces gonadotrophin dose required for controlled ovarian stimulation in women with unexplained infertility," Human Reproduction, vol. 18, no. 8, pp. 1588-1597, 2003.

[30] K. Oktay, E. Buyuk, N. Libertella, M. Akar, and Z. Rosenwaks, "Fertility preservation in breast cancer patients: a prospective controlled comparison of ovarian stimulation with tamoxifen and letrozole for embryo cryopreservation," Journal of Clinical Oncology, vol. 23, no. 19, pp. 4347-4353, 2005.

[31] A. Leader, M. Lishner, J. Michaeli, and A. Revel, "Fertility considerations and preservation in haemato-oncology patients undergoing treatment," British Journal of Haematology, vol. 153, no. 3, pp. 291-308, 2011.

[32] K. Oktay, "Ovarian tissue cryopreservation and transplantation: preliminary findings and implications for cancer patients," Human Reproduction Update, vol. 7, no. 6, pp. 526$534,2001$.

[33] J. Hirshfeld-Cytron, C. Gracia, and T. K. Woodruff, "Nonmalignant diseases and treatments associated with primary ovarian failure: an expanded role for fertility preservation," Journal of Women's Health, vol. 20, no. 10, pp. 1467-1477, 2011.

[34] N. Noyes, P. A. Labella, J. Grifo, and J. M. Knopman, “Oocyte cryopreservation: a feasible fertility preservation option for reproductive age cancer survivors," Journal of Assisted Reproduction and Genetics, vol. 27, no. 8, pp. 495-499, 2010.

[35] M. Sonmezer and K. Oktay, "Fertility preservation in young women undergoing breast cancer therapy," Oncologist, vol. 11, no. 5, pp. 422-434, 2006.

[36] N. Y. Kim, U. Ryoo, D. Y. Lee, M. J. Kim, B. K. Yoon, and D. Choi, "The efficacy and tolerability of short-term lowdose estrogen-only add-back therapy during post-operative GnRH agonist treatment for endometriosis," European Journal of Obstetrics Gynecology and Reproductive Biology, vol. 154, no. 1, pp. 85-89, 2011.

[37] M. von Wolff, C. J. Thaler, T. Frambach et al., "Ovarian stimulation to cryopreserve fertilized oocytes in cancer patients can be started in the luteal phase," Fertility and Sterility, vol. 92, no. 4, pp. 1360-1365, 2009.

[38] R. C. Chian, L. Gilbert, J. Y. J. Huang et al., "Live birth after vitrification of in vitro matured human oocytes," Fertility and Sterility, vol. 91, no. 2, pp. 372-376, 2009.

[39] R. C. Chian, J. Y. J. Huang, L. Gilbert et al., "Obstetric outcomes following vitrification of in vitro and in vivo matured oocytes," Fertility and Sterility, vol. 91, no. 6, pp. 2391-2398, 2009.
[40] R. C. Chian, J. H. Lim, and S. L. Tan, "State of the art in invitro oocyte maturation," Current Opinion in Obstetrics and Gynecology, vol. 16, no. 3, pp. 211-219, 2004.

[41] C. Wu, R. Rui, J. Dai et al., "Effects of cryopreservation on the developmental competence, ultrastructure and cytoskeletal structure of porcine oocytes," Molecular Reproduction and Development, vol. 73, no. 11, pp. 1454-1462, 2006.

[42] Y. X. Cao, Q. Xing, L. Li et al., "Comparison of survival and embryonic development in human oocytes cryopreserved by slow-freezing and vitrification," Fertility and Sterility, vol. 92, no. 4, pp. 1306-1311, 2009.

[43] Y. Cao, Q. Xing, Z. G. Zhang, Z. L. Wei, P. Zhou, and L. Cong, "Cryopreservation of immature and in-vitro matured human oocytes by vitrification," Reproductive BioMedicine Online, vol. 19, no. 3, pp. 369-373, 2009.

[44] S. U. Chen, Y. R. Lien, H. F. Chen, L. J. Chang, Y. Y. Tsai, and Y. S. Yang, "Observational clinical follow-up of oocyte cryopreservation using a slow-freezing method with 1,2-propanediol plus sucrose followed by ICSI," Human Reproduction, vol. 20, no. 7, pp. 1975-1980, 2005.

[45] X. H. Li, S. U. Chen, X. Zhang et al., "Cryopreserved oocytes of infertile couples undergoing assisted reproductive technology could be an important source of oocyte donation: a clinical report of successful pregnancies," Human Reproduction, vol. 20, no. 12, pp. 3390-3394, 2005.

[46] M. Kuwayama, G. Vajta, O. Kato, and S. P. Leibo, "Highly efficient vitrification method for cryopreservation of human oocytes," Reproductive BioMedicine Online, vol. 11, no. 3, pp. 300-308, 2005.

[47] A. Borini, C. Lagalla, M. A. Bonu, V. Bianchi, C. Flamigni, and G. Coticchio, "Cumulative pregnancy rates resulting from the use of fresh and frozen oocytes: 7 years' experience," Reproductive BioMedicine Online, vol. 12, no. 4, article 2164, pp. 481-486, 2006.

[48] J. Barritt, M. Luna, M. Duke et al., "Report of four donorrecipient oocyte cryopreservation cycles resulting in high pregnancy and implantation rates," Fertility and Sterility, vol. 87, no. 1, pp. 189.e13-189.e17, 2007.

[49] E. Lucena, D. P. Bernal, C. Lucena, A. Rojas, A. Moran, and A. Lucena, "Successful ongoing pregnancies after vitrification of oocytes," Fertility and Sterility, vol. 85, no. 1, pp. 108-111, 2006.

[50] M. Antinori, E. Licata, G. Dani, F. Cerusico, C. Versaci, and S. Antinori, "Cryotop vitrification of human oocytes results in high survival rate and healthy deliveries," Reproductive BioMedicine Online, vol. 14, no. 1, article 2548, pp. 72-79, 2007.

[51] A. Cobo, M. Kuwayama, S. Pérez, A. Ruiz, A. Pellicer, and J. Remohí, "Comparison of concomitant outcome achieved with fresh and cryopreserved donor oocytes vitrified by the Cryotop method," Fertility and Sterility, vol. 89, no. 6, pp. 1657-1664, 2008.

[52] L. Parmegiani, G. E. Cognigni, S. Bernardi et al., "Freezing within $2 \mathrm{~h}$ from oocyte retrieval increases the efficiency of human oocyte cryopreservation when using a slow freezing/rapid thawing protocol with high sucrose concentration," Human Reproduction, vol. 23, no. 8, pp. 1771-1777, 2008.

[53] G. D. Smith, P. C. Serafini, J. Fioravanti et al., "Prospective randomized comparison of human oocyte cryopreservation with slow-rate freezing or vitrification," Fertility and Sterility, vol. 94, no. 6, pp. 2088-2095, 2010.

[54] L. Rienzi, S. Romano, L. Albricci et al., "Embryo development of fresh "versus" vitrified metaphase II oocytes after 
ICSI: a prospective randomized sibling-oocyte study," Human Reproduction, vol. 25, no. 1, pp. 66-73, 2010.

[55] A. Cobo, J. L. Romero, S. Pérez, M. J. de Los Santos, M. Meseguer, and J. Remohí, "Storage of human oocytes in the vapor phase of nitrogen," Fertility and Sterility, vol. 94, no. 5, pp. 1903-1907, 2010.

[56] E. Fuku, L. Xia, and B. R. Downey, "Ultrastructural changes in bovine oocytes cryopreserved by vitrification," Cryobiology, vol. 32, no. 2, pp. 139-156, 1995.

[57] A. I. Younis, M. Toner, D. F. Albertini, and J. D. Biggers, "Cryobiology of non-human primate oocytes," Human Reproduction, vol. 11, no. 1, pp. 156-165, 1996.

[58] E. Shalom-Paz, B. Almog, F. Shehata et al., "Fertility preservation for breast-cancer patients using IVM followed by oocyte or embryo vitrification," Reproductive BioMedicine Online, vol. 21, no. 4, pp. 566-571, 2010.

[59] A. Trounson and L. Mohr, "Human pregnancy following cryopreservation, thawing and transfer of an eight-cell embryo," Nature, vol. 305, no. 5936, pp. 707-709, 1983.

[60] G. H. Zeilmaker, A. T. Alberda, and I. van Gent, "Two pregnancies following transfer of intact frozen-thawed embryos," Fertility and Sterility, vol. 42, no. 2, pp. 293-296, 1984.

[61] M. Toner, E. G. Cravalho, and D. R. Armant, "Water transport and estimated transmembrane potential during freezing of mouse oocytes," Journal of Membrane Biology, vol. 115, no. 3, pp. 261-272, 1990.

[62] D. G. Whittingham, "Survival of mouse embryos after freezing and thawing," Nature, vol. 233, no. 5315, pp. 125-126, 1971.

[63] E. Porcu, R. Fabbri, G. Damiano et al., "Clinical experience and applications of oocyte cryopreservation," Molecular and Cellular Endocrinology, vol. 169, no. 1-2, pp. 33-37, 2000.

[64] R. Fabbri, E. Porcu, T. Marsella, G. Rocchetta, S. Venturoli, and C. Flamigni, "Human oocyte cryopreservation: new perspectives regarding oocyte survival," Human Reproduction, vol. 16, no. 3, pp. 411-416, 2001.

[65] J. J. Stachecki, J. Cohen, T. Schimmel, and S. M. Willadsen, "Fetal development of mouse oocytes and zygotes cryopreserved in a nonconventional freezing medium," Cryobiology, vol. 44, no. 1, pp. 5-13, 2002.

[66] J. Boldt, N. Tidswell, A. Sayers, R. Kilani, and D. Cline, "Human oocyte cryopreservation: 5-year experience with a sodium-depleted slow freezing method," Reproductive BioMedicine Online, vol. 13, no. 1, article 2231, pp. 96-100, 2006.

[67] J. A. Grifo and N. Noyes, "Delivery rate using cryopreserved oocytes is comparable to conventional in vitro fertilization using fresh oocytes: potential fertility preservation for female cancer patients," Fertility and Sterility, vol. 93, no. 2, pp. 391396, 2010.

[68] V. Bianchi, G. Coticchio, V. Distratis, N. di Giusto, C. Flamigni, and A. Borini, "Differential sucrose concentration during dehydration $(0.2 \mathrm{~mol} / \mathrm{l})$ and rehydration $(0.3 \mathrm{~mol} / \mathrm{l})$ increases the implantation rate of frozen human oocytes," Reproductive BioMedicine Online, vol. 14, no. 1, article 2455, pp. 64-71, 2007.

[69] S. A. Nottola, G. Macchiarelli, G. Coticchio et al., "Ultrastructure of human mature oocytes after slow cooling cryopreservation using different sucrose concentrations," Human Reproduction, vol. 22, no. 4, pp. 1123-1133, 2007.

[70] G. M. Fahy, D. I. Levy, and S. E. Ali, "Some emerging principles underlying the physical properties, biological actions, and utility of vitrification solutions," Cryobiology, vol. 24, no. 3, pp. 196-213, 1987.
[71] W. F. Rall, M. J. Wood, C. Kirby, and D. G. Whittingham, "Development of mouse embryos cryopreserved by vitrification," Journal of Reproduction and Fertility, vol. 80, no. 2, pp. 499-504, 1987.

[72] G. Vajta and M. Kuwayama, "Improving cryopreservation systems," Theriogenology, vol. 65, no. 1, pp. 236-244, 2006.

[73] Z. P. Nagy, C. C. Chang, D. B. Shapiro, D. P. Bernal, H. I. Kort, and G. Vajta, "The efficacy and safety of human oocyte vitrification," Seminars in Reproductive Medicine, vol. 27, no. 6, pp. 450-455, 2009.

[74] S. P. Leibo and T. B. Pool, "The principal variables of cryopreservation: solutions, temperatures, and rate changes," Fertility and Sterility, vol. 96, no. 2, pp. 269-276, 2011.

[75] S. Seki and P. Mazur, "The dominance of warming rate over cooling rate in the survival of mouse oocytes subjected to a vitrification procedure," Cryobiology, vol. 59, no. 1, pp. 75-82, 2009.

[76] J. Liebermann, M. J. Tucker, and E. S. Sills, "Cryoloop vitrification in assisted reproduction: analysis of survival rates in $>1000$ human oocytes after ultra-rapid cooling with polymer augmented cryoprotectants," Clinical and Experimental Obstetrics and Gynecology, vol. 30, no. 2-3, pp. 125-129, 2003.

[77] T. K. Yoon, H. M. Chung, J. M. Lim, S. Y. Han, J. J. Ko, and K. Y. Cha, "Pregnancy and delivery of healthy infants developed from vitrified oocytes in a stimulated in vitro fertilizationembryo transfer program," Fertility and Sterility, vol. 74, no. 1, pp. 180-181, 2000.

[78] L. Parmegiani, A. Accorsi, G. E. Cognigni, S. Bernardi, E. Troilo, and M. Filicori, "Sterilization of liquid nitrogen with ultraviolet irradiation for safe vitrification of human oocytes or embryos," Fertility and Sterility, vol. 94, no. 4, pp. 1525$1528,2010$.

[79] A. Camus, P. Clairaz, A. Ersham, A. L. van Kappel, G. Savić, and C. Staub, "The comparison of the process of five different vitrification devices," Gynecologie Obstetrique Fertilite, vol. 34, no. 9, pp. 737-745, 2006.

[80] F. AbdelHafez, J. Xu, J. Goldberg, and N. Desai, "Vitrification in open and closed carriers at different cell stages: assessment of embryo survival, development, DNA integrity and stability during vapor phase storage for transport," BMC Biotechnology, vol. 11, p. 29, 2011.

[81] A. Cobo, J. Bellver, J. Domingo et al., "New options in assisted reproduction technology: the Cryotop method of oocyte vitrification," Reproductive BioMedicine Online, vol. 17, no. 1, pp. 68-72, 2008.

[82] C. C. Chang, C. J. Lin, L. Y. Sung, H. I. Kort, X. C. Tian, and Z. P. Nagy, "Impact of phase transition on the mouse oocyte spindle during vitrification," Reproductive BioMedicine Online, vol. 22, no. 2, pp. 184-191, 2011.

[83] D. K. Gardner, C. B. Sheehan, L. Rienzi, M. Katz-Jaffe, and M. G. Larman, "Analysis of oocyte physiology to improve cryopreservation procedures," Theriogenology, vol. 67, no. 1, pp. 64-72, 2007.

[84] P. M. Ciotti, E. Porcu, L. Notarangelo, O. Magrini, A. Bazzocchi, and S. Venturoli, "Meiotic spindle recovery is faster in vitrification of human oocytes compared to slow freezing," Fertility and Sterility, vol. 91, no. 6, pp. 2399-2407, 2009.

[85] C. G. Almodin, V. C. Minguetti-Camara, C. L. Paixao, and P. C. Pereira, "Embryo development and gestation using fresh and vitrified oocytes," Human Reproduction, vol. 25, no. 5, pp. 1192-1198, 2010.

[86] A. Cobo, M. Meseguer, J. Remohí, and A. Pellicer, "Use of cryo-banked oocytes in an ovum donation programme: a prospective, randomized, controlled, clinical trial," Human Reproduction, vol. 25, no. 9, pp. 2239-2246, 2010. 


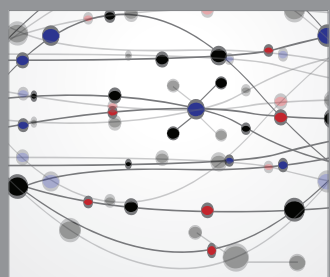

The Scientific World Journal
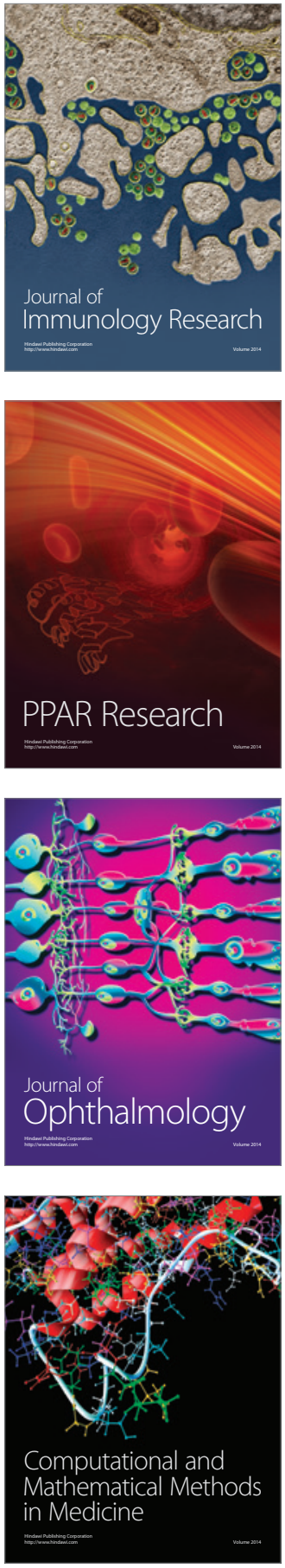

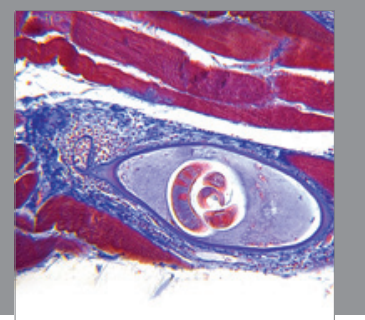

Gastroenterology

Research and Practice
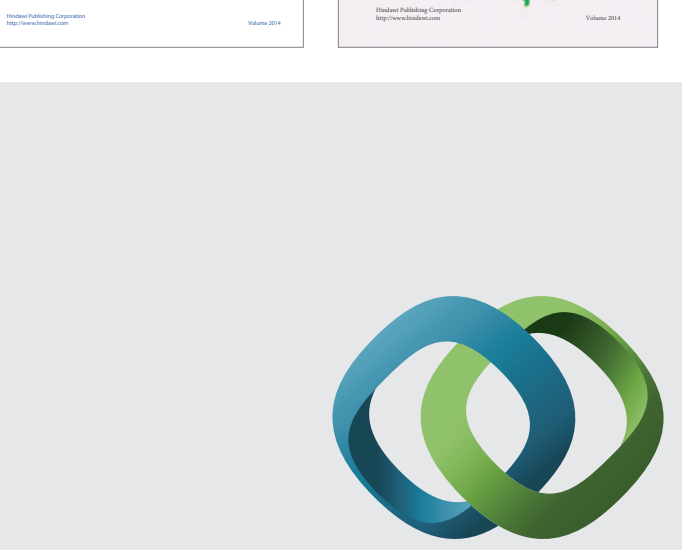

\section{Hindawi}

Submit your manuscripts at

http://www.hindawi.com
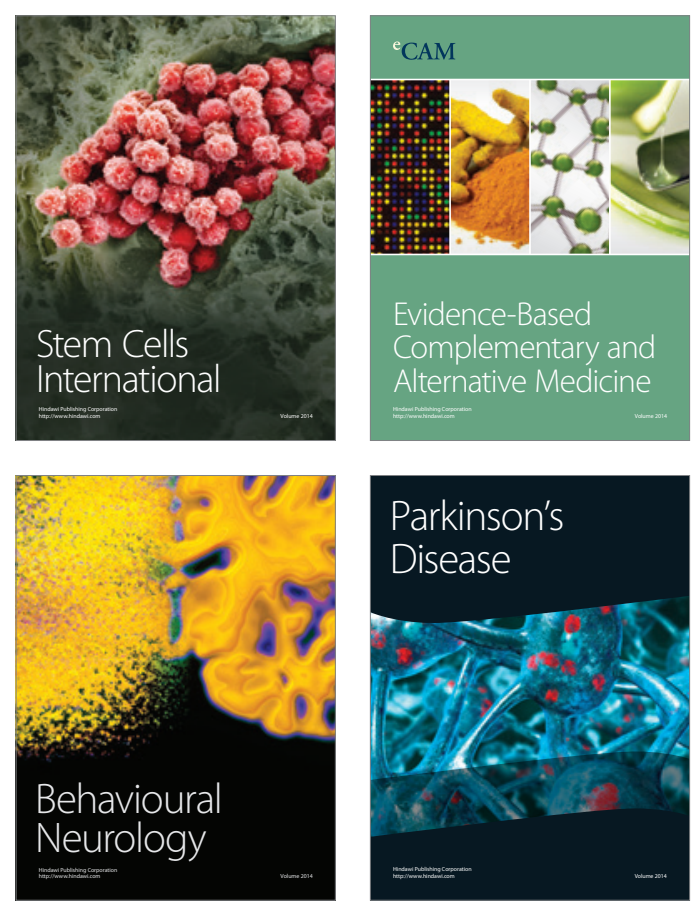

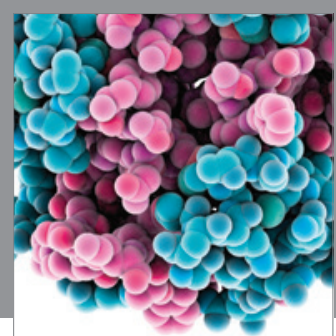

Journal of
Diabetes Research

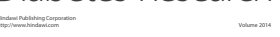

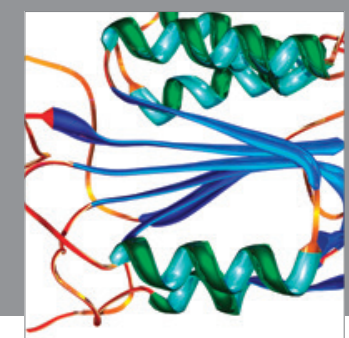

Disease Markers
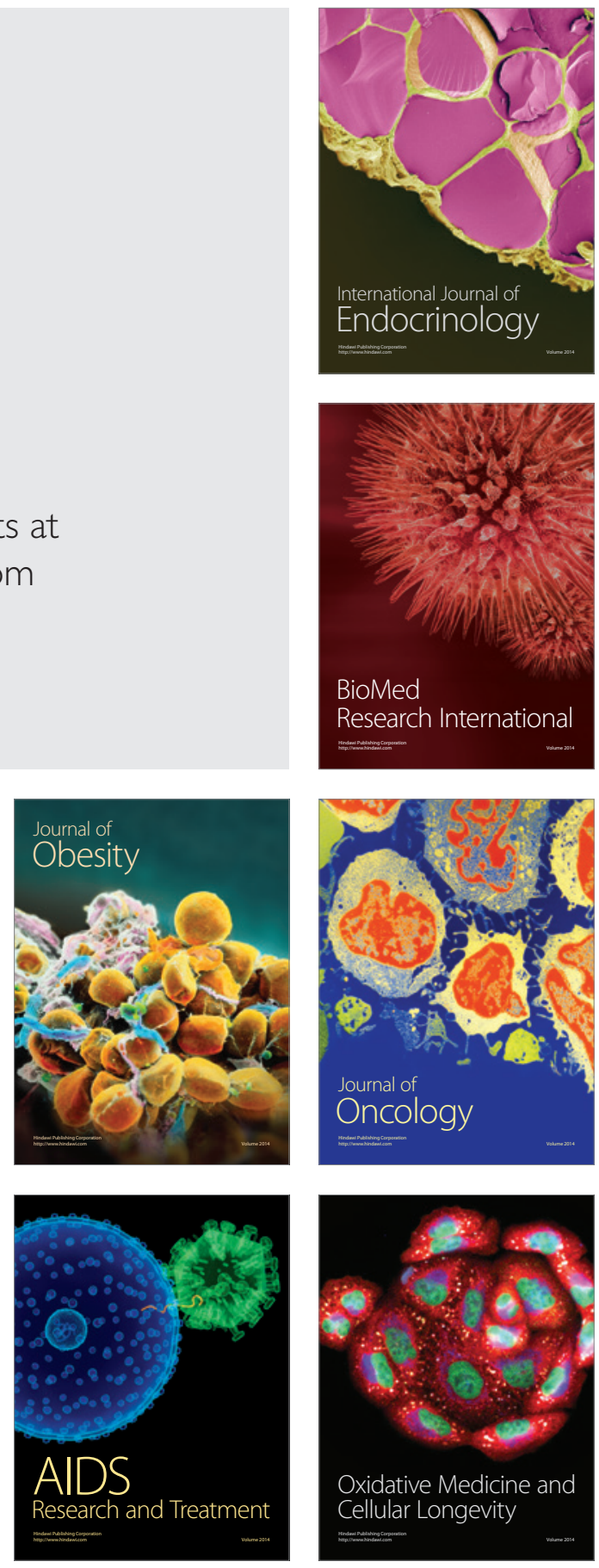